\title{
¿Cerca de la revolución? \\ Datos cuantitativos e interpretaciones de las encuestas sobre las distintas modalidades de apoyo a la violencia revolucionaria en Argentina, 1970 - 1973.
}

\author{
Close to revolution? \\ Quantitative data and interpretations of the surveys on the different modalities of support for \\ revolutionary violence in Argentina, 1970 - 1973.
}

Daniel Lvovich*

\begin{abstract}
Resumen: En este trabajo sistematizamos el conocimiento sobre las distintas modalidades de respaldo a la violencia revolucionaria en Argentina a comienzos de la década de 1970 obtenido en distintas encuestas de opinión. Asimismo, explicamos los modos en que las nociones referidas a la violencia revolucionaria fueron construidas en el diseño de los instrumentos analíticos, y evaluamos los resultados cuantitativos y las interpretaciones que han recibido los datos obtenidos.
\end{abstract}

Palabras clave: Violencia revolucionaria, Encuestas de opinión, Argentina, opinión pública

\begin{abstract}
In this article we systematized the knowledge on the different modalities of support for revolutionary violence in Argentina at the beginning of the 1970s obtained in different opinion polls. Also we explain the ways in which the notions referring to revolutionary violence were constructed in the design of the analytical instruments, and we evaluate the quantitative results and the interpretations that have received the obtained data.
\end{abstract}

Keywords: Revolutionary violence, Opinion polls, Argentina, public opinion.

Recibido: 8 abril 2019 Aceptado: 21 mayo 2019

Existe en la vida política y en las ciencias sociales argentinas un debate que con frecuencia se activa, referido a la naturaleza y la dimensión del respaldo con el que podrían haber contado las organizaciones que adoptaron la violencia revolucionaria como método de lucha desde la década de 1960.

Ese debate resulta sumamente relevante, ya que busca dar cuenta de uno de los modos de vinculación de distintos sectores de la sociedad argentina con los proyectos de cambio revolucionario y en particular con aquellas estrategias insurgentes que abrazaron la vía armada. Diversos trabajos historiográficos han intentado explicar la adhesión, apoyo o simpatía hacia los grupos guerrilleros, al que se considera un fenómeno distinto al apoyo militante o a la vinculación política directa. En general, esas formas de adhesión inestable o simpatía, ha sido considerada amplia para la década de 1960 y comienzos

\footnotetext{
* Programa de Historia Contemporánea, Universidad Nacional de General Sarmiento/Consejo Nacional de Investigaciones Científicas y Técnicas, República Argentina.dlvovich@ungs.edu.ar
} 
de la de 1970, en función de diversos factores. En algunos casos se señala que el fenómeno se debe leer en el largo plazo, en el seno de una sociedad en que la violencia represiva estatal resultaba habitual, lo que permitía considerar al recurso a la violencia de los grupos insurgentes como una respuesta justa y legítima. ${ }^{1}$ En particular la brutalidad represiva de la llamada Revolución Argentina y su falta de legitimidad "....alentó la idea de que disputarle el monopolio de la violencia era un hecho políticamente aceptable."2 Esa forma de legitimación, en algunos caos, alcanzó incluso a sectores de la derecha política ${ }^{3} \mathrm{E}$ apoyo de Perón y la legitimidad que brindó el respaldo de sectores de la Iglesia a los grupos revolucionarios ocupan un rol relevante en la explicación del respaldo social a las acciones guerrilleras. ${ }^{4}$ El contexto de radicalización política general es entendido asimismo como un elemento indispensable para la comprensión de la expansión del apoyo social a los grupos revolucionarios. ${ }^{5}$ Las propias acciones de los grupos guerrilleros podían provocar simpatía sin que esto se tradujera en apoyo político directo, de modo que el apoyo informal se debería a que se considerara a los militantes como jóvenes voluntariosos, sin distinción de la organización a la que pertenecían" 6

Entre las fuentes a la que se recurre para sustentar argumentaciones en este debate suelen contarse un conjunto de encuestas de opinión desarrolladas en los años en que el fenómeno de la violencia revolucionaria se desarrollaba con fuerza. Dichas fuentes permiten orientar el debate ya no solo hacia la naturaleza o causas de las diversas formas de adhesión o rechazo, sino también hacia una estimación del volumen de dicho fenómeno.

En este trabajo buscamos sistematizar el conocimiento proveniente de tales fuentes, presentando de ese modo un panorama completo de la información disponible al respecto, para lo cual es una precondición dar cuenta del desarrollo de la historia de las encuestas de opinión pública en Argentina. Pero también buscamos explicar los modos en que las nociones referidas a la violencia revolucionaria fueron construidas en el diseño de los instrumentos analíticos, ya que el empleo de estas categorías resulta determinante para la comprensión en la propia época del fenómeno, influye sin dudas en las respuestas que puede promover y no deja de tener efectos sobre nuestra propia manera de observar e intentar comprender aquel pasado.

Para ello presentaremos en primer lugar algunos elementos que permitan comprender la emergencia de las encuestas de opinión en la Argentina, de manera de dar cuenta del desarrollo de las empresas dedicadas a ese tipo de investigaciones y del interés del estado argentino, en etapas dictatoriales, por desarrollar y aprovechar estos instrumentos.

\footnotetext{
${ }^{1}$ Entre otros, Pablo Pozzi Por las sendas argentinas: El PRT-ERP. La guerrilla marxista, Buenos Aires, EUDEBA, 2001 y "Para continuar con la polémica sobre la lucha armada" en Lucha armada en la Argentina, N 5, 2006.

2 Pilar Calveiro: "Antiguos y nuevos sentidos de la política y la violencia" en Lucha Armada en la Argentina, N 4, 2005 , p.13. Perspectivas similares se encuentran entre otros en Oscar Anzorena, Tiempo de violencia y utopia. Del golpe de Onganía (1966) al golpe de Videla (1970), Buenos Aires, Ediciones del Pensamiento Nacional, 1998 y Maristella Svampa, Maristella Svampa, "El populismo imposible y sus actores" en. Daniel James (dir.) Nueva Historia Argentina; tomo 9, Violencia, proscripción y autoritarismo; Buenos Aires, Sudamericana, 2003.

3Leandro Inchauspe, "No justifico la violencia, pero..." La dirigencia política cordobesa y la lucha armada, Córdoba 1970-1972", Documento de Trabajo No 13 - Córdoba, 2007, disponible en http://historiapolitica.com/datos/biblioteca/cean13.pdf

${ }^{4}$ Richard Gillespie, Soldados de Perón. Los Montoneros, Buenos Aires, Grijalbo, 1987; Claudia F. Touris, "Iglesia católica, dictaduras y memorias en conflicto en Brasil y Argentina “, Archives de sciences sociales des religions [En ligne], 170 | avril-juin 2015. URL: http://journals.openedition.org/assr/26877 ; DOI : 10.4000/assr.26877

5 Adamini, M. (2009) El consenso social de Montoneros entre 1970 y 1972 [en línea]. Trabajo final de grado. Universidad Nacional de La Plata. Facultad de Humanidades y Ciencias de la Educación. Disponible en:

http://www.memoria.fahce.unlp.edu.ar/tesis/te.549/te.549.pdf. En este trabajo se revisan las principales hipótesis acerca de la expansión de lo que la autora denomina el "consenso social" a Montoneros.

6 Pablo Pozzi, "La guerrilla argentina y las masas: el ERP y su inserción”, en: Tempo e Argumento, Florianopolis, N¹6, 2015, p.112
} 
A continuación, exponemos los elementos fundamentales de las encuestas de opinión pública relativas a la violencia de las que conocemos su existencia y las diferentes interpretaciones que ha recibido ese corpus de encuestas.

En base a ese conjunto de informaciones e interpretaciones proponemos por último una evaluación de los datos cuantitativos y de las modalidades cualitativas de construcción de la información que brindan las encuestas consideradas, intentado explicar el impacto de los modos de interrogar en los resultados de las encuestas y destacando las marcadas diferencias en las respuestas, tanto en perspectiva sincrónica cuanto considerando criterios regionales y clasistas.

\section{Una introducción a la historia de las encuestas de opinión pública en Argentina}

En contraste con la rápida expansión de la encuesta como método de investigación social en Europa en las décadas de 1950 y 1960, la evolución de los estudios de opinión pública en América Latina resultó algo posterior, ya que se desarrolló en un momento "en que la innovación técnica alcanza el grado de solidez y estandarización suficiente para industrializarse y orientarse a fines comerciales." 7

Sin embargo, en Argentina los antecedentes se remontan a comienzos de la década de 1940, cuando miembros del Instituto de Sociología de la UBA se vincularon con el Instituto Americano de la Opinión Pública, dirigido por George Gallup. En el primer número del Boletín del Instituto de Sociología de la UBA, en 1942, se manifestó la idea de crear un Instituto de Opinión Pública, adaptando el modelo de Gallup a la realidad argentina, iniciativa que no llegó a plasmarse. Para 1956 se registra la existencia en el ámbito privado de un Instituto Argentino de Opinión Pública, dirigido por Alfredo Infante, que en 1957 desarrolló una investigación sobre hábitos y preferencias de los porteños en relación a los diarios, con una muestra de más de 6.000 casos. En 1960 el Instituto desarrolló estudios sobre las elecciones realizadas ese año en EEUU y en Argentina. .8

El uso de esta herramienta se expandió a lo largo de la década de 1950 y comienzos de la de 1960, proliferación que se debió al interés profesional y comercial de abrir un mercado de encuestas de opinión pública, que tenía como antecedente a las empresas de investigación de mercado. El uso intensivo de las encuestas de opinión en las empresas de estudios de mercado antes que en los institutos de opinión pública, acerca el caso argentino al francés. ${ }^{9}$ En 1959 se creó en Buenos Aires el Instituto de Psicología Social Aplicada (IPSA), empresa de estudios de mercado dirigida por Miguel Gorfinkiel y Carmen Zayuelas, llevo a cabo investigaciones en temas políticos, además de las encuestas propiamente de mercado. Los temas estudiados han incluido las imágenes de empresas y otras instituciones; hábitos de lectura de periódicos y de consumos de televisión; las actitudes de los jóvenes en las principales ciudades argentinas, estudios preelectorales; y una variedad de encuestas generales sobre temas políticos y de actualidad. ${ }^{10}$

En la década de 1960 se desarrollaron nuevas empresas de marketing como Analistas de Empresa y Consultores de Dirección (A\&C), presidida por Carlos Kaplan, que realizó encuestas políticas para el gobierno militar establecido en 1966; y una filial local del Instituto Gallup, aunque dedicado mayoritariamente a los estudios de mercado. De modo simultáneo se desarrollaron instituciones e iniciativas destinadas a auscultar específicamente la opinión pública. José Miguens, sociólogo católico de larga trayectoria intelectual y política, creador y primer director del Departamento de Sociología de la

\footnotetext{
${ }_{7}$ Claudia Daniel. Números públicos. Las estadísticas en Argentina (1990 - 2010), Buenos Aires, FCE, 2013, p.111

8 Andres Shoai, "La estratificación social en loe orígenes de las encuestas de opinión pública en Argentina", IX jornadas de Sociología, Facultad de Ciencias Sociales, Universidad de Buenos Aires, 2011, pp. 2 y 3, disponible en: cdsa.aacademica.org/000034/591.pdf

9 Claudia Daniel, op.cit., 111, Gabriel Vommaro, "Lo que quiere la gente”. Los sondeos de opinión y el espacio de la comunicación politica en la Argentina (1983-1999), Buenos Aires, Prometeo, 2008, 72.

${ }^{10}$ Frederick Turner, "The study of Argentina Politics through Survey Research”, Latin American Research Review, 10, 1975 , p.91.
} 
Universidad Católica Argentina, tuvo un rol destacadísimo en este aspecto. Miguens trabajó en la primera encuesta de opinión pública de 1958, que inauguraría una serie de estudios realizados por el sociólogo para la Secretaría de Informaciones del Estado de la Presidencia de la Nación durante el gobierno de Arturo Frondizi (1958-1962). Miguens ejecutó estos trabajos desde el Centro de Investigaciones Motivacionales, el Centro Argentino de Encuestas y el Instituto Lanús. Sin embargo, según rememoraba Manuel Mora y Araujo - uno de los más destacados encuestadores del período, sociólogo por la UBA de importante trayectoria académica - no había un real interés en el Estado durante los años del desarrollismo por construir un conocimiento empíricamente informado de la opinión pública, por lo que las investigaciones de Miguens resultaron más un producto de sus vinculaciones con funcionarios de la Secretaría de Informaciones que de un interés estatal sistemático. ${ }^{11}$

Además de estos emprendimientos, diversos intelectuales realizaron en ocasiones encuestas de opinión desde la década de 1960. Justamente Manuel Mora y Araujo, realizó su primera encuesta política en 1965 para el dirigente peronista Antonio Cafiero, aunque se trató de un trabajo puntual y no de una investigación sistemática. También el sociólogo, militante de la nueva izquierda y experto en comunicación Heriberto Muraro recordaba haber realizado encuestas de opinión pública en la época del Presidente Arturo Illia (1963-1966), pero cuando el golpe militar de 1966 clausuró las vías democráticas, volvió a dedicarse a las encuestas comerciales. ${ }^{12}$

Los trabajos y el rol institucional de Gino Germani también resultaron determinantes para la extensión de la aplicación sistemática de encuestas de opinión. Tras el golpe de Estado de 1955, Germani se desempeñó como director de la carrera de Sociología y del Departamento de Sociología de la UBA, creados en 1957. En tales funciones Germani fue una figura clave del pronunciado proceso de modernización cultural y académico que atravesó la Argentina entre 1955 y 1966. ${ }^{13}$ Desde 1957 Germani dirigió, entre otros, el proyecto de investigación "Etnocentrismo y actitudes autoritarias", en el que se evidencia la influencia de las preocupaciones frankfurtianas por la problemática del totalitarismo y la personalidad autoritaria y basado en un muy extenso trabajo de campo. ${ }^{14}$ Sin embargo, a Germani le importaba menos dar cuenta de las fluctuaciones de la opinión pública que explicar las actitudes autoritarias y en definitiva, intentar exponer los rasgos básicos de la estructura misma de la sociedad argentina. ${ }^{15}$

Por supuesto, el escrutinio de la opinión de distintos segmentos de la sociedad argentina también fue realizado por investigadores y agencias extranjeras, en particular norteamericanos, en el periodo. Tal es el caso del controvertido Proyecto Camelot, realizado por la Organización de Investigaciones Científicas para Operaciones Especiales (OIES) para el ejército de Estados Unidos. El proyecto, iniciado en 1963 y destinado a aplicarse en América Latina y otras regiones se proponía buscar los medios para eliminar las causas de las revoluciones y actos de rebeldía, o conocer los mejores medios para oponerse a ellas. Tras las denuncias en su contra formuladas en Chile, el proyecto fue desactivado formalmente en 1965. ${ }^{16}$ Para el caso argentino, una encuesta de ese proyecto demostró que las actitudes anti norteamericanas eran menos generalizadas en la población que lo que podría esperarse en función de los discursos políticos y los informes de la prensa. En 1965 Jeane Kirkpatrick, correlacionó en el análisis de su encuesta las simpatías peronistas con los miembros más autoritarios de la clase baja, mientras en su

\footnotetext{
11 Shoai,op. cit., op. cit., pp. 4 y 8.

12 Vommaro, p.73.

13 Cf. Alejandro Blanco, Razón y Modernidad. Gino Germani y la Sociología en la Argentina, Buenos Aires, Siglo XXI; Oscar Terán, Nuestros años sesenta, Buenos Aires, Punto Sur, 1991, pp. 3 y ss.

14 Daniel Lvovich, "Gino Germani, Argentine Sociology and the Study of Antisemitism" in Marcel Stoetzler (ed) Antisemitism and the Constitution of Sociology, Lincoln, Nebraska, University of Nebraska Press, 2014, pp. 304 y ss.

15 Shoai,op. cit., p. 5

16 Ver al respecto Irving Louis Horowitz, "Vida y muerte del Proyecto Camelot", en Revista de Ciencias Sociales, núm. 2, junio de 1966.
} 
estudio sobre los estudiantes universitarios, mientras en base a este tipo de sondeos David Nasatir afirmaba encontrar un vínculo entre el contacto con la universidad y el apoyo a un sistema democrático. ${ }^{17}$

Se ha señalado que la asociación de las encuestas de opinión pública con los principios democráticos y las libertades individuales pertenece al momento mismo de la emergencia pública de los sondeos como una innovación técnica, en la defensa y justificación de la herramienta que hizo su primer promotor, George Gallup. ${ }^{18}$ Sin embargo, podemos sostener que para el caso argentino la ampliación del uso de estas técnicas, y sobre todo, la vocación estatal de recoger datos de opinión a través de este medio se verificará en el contexto de la autodenominada Revolución Argentina, dictadura militar que, con distintas etapas y liderazgos, se desarrolló entre 1966 y 1973. De hecho, la primer gran experiencia de la firma A\&C fue una compulsa efectuada el 30 de junio de 1966, para calibrar el apoyo de la población al régimen militar recientemente instaurado. ${ }^{19}$ Guillermo O'Donnell ha considerado esa encuesta en uno de sus textos principales, gracias a lo que podemos saber que el 66\% de los encuestados aprobaba al régimen militar explícitamente y solo el $6 \%$ se oponía al mismo. ${ }^{20}$ Exactamente dos años más tarde, y cuando las transformaciones sociales y económicas introducidas por la dictadura habían generado un malestar no siempre visible, la revista Primera Plana le encargó a la misma empresa A\&C un sondeo de opinión pública sobre el régimen de Onganía., que dio como resultado un extendido rechazo al régimen militar. ${ }^{21}$

Se ha señalado que la dictadura militar instaurada en 1976 apeló a la realización sistemática de encuestas y sondeos con el objetivo de relevar la opinión pública sobre temas vinculados al contexto social, económico y político, la imagen del gobierno, y el rol de las FFAA. Estas investigaciones eran realizadas por las propias agencias estatales de inteligencia e información. ${ }^{22}$ Sabemos ahora que también la llamada Revolución Argentina recurrió al uso de estos métodos, evidenciando de un uso instrumental de las ciencias sociales por parte de agencias estatales en el marco de un régimen dictatorial que combinaba unas perspectivas conservadoras y comunitaristas, y unas prácticas altamente represivas, con unas utopías modernizadoras de la sociedad y del estado que, podemos hipotetizar, contribuyen a explicar la acogida de las modernas técnicas de recolección de datos.

Junto a ello, hacia 1970 la publicación de resultados de encuestas de opinión política por los medios de comunicación era frecuente, como un indicador de la confianza capacidad de reflejar y de influir en la opinión pública. En diciembre de 1970 Correo de la Tarde presentaba la publicación de una encuesta con este encabezado, que ejemplifica ese proceso:

\footnotetext{
${ }^{17}$ Cf Turner, op.cit., p.90

18 Daniel, op. cit., op. cit., 109

${ }^{19}$ Vommaro, p.45.

${ }^{20}$ Según otra encuesta $77 \%$ de los entrevistados respondió afirmativamente a la pregunta “¿Cree usted que la revolución del 28 de junio fue necesaria?" Correo de la tarde, 6-12 de junio de 1967 (1000 entrevistados en la ciudad de Buenos Aires, metodología no informada)

Guillermo O’Donnell, El Estado Burocrático autoritario, Buenos Aires, Editorial de Belgrano, 1996 [1982], pp. 65-66.

${ }^{21}$ La metodología de la encuesta, la zona geográfica en que se aplicó y el tamaño de la muestra no fueron informados. Los resultados publicados daban cuenta del desgaste del régimen dictatorial: el sesenta por ciento de los consultados no asignaba "nada bueno" al gobierno de Onganía y para el setenta por ciento de los consultados Onganía era "igual o peor" que el derrocado Illia. El análisis segmentado por clases sociales muestra que el régimen contaba con un pronunciado apoyo en las clases altas, motivado fundamentalmente en la valoración positiva de la "estabilidad económica", aun cuando en ese mismo sector un 54 \% se muestra insatisfecho con la situación económica, insatisfacción que alcanza al $80 \%$ entre los encuestados de clase media y al $86 \%$ entre los obreros consultados. Respondieron que el gobierno no había hecho "Nada bueno" el 14, 41 y 80 por ciento de los consultados de clase alta, media y baja respectivamente. Todo ello contribuye a fortalecer la idea del marcado carácter clasista del régimen, y de la existencia de una oposición obrera muy amplia, aun cuando la conflictividad social no se había manifestado con toda su virulencia en aquel momento en las áreas centrales del país, aunque en si en provincias como Tucumán y Chaco. Pero también da cuenta de la enorme volatilidad de la llamada "opinión pública" si se la toma como la expresión de un bloque social homogéneo e indiferenciado. Primera Plana, 25 de junio al $1^{\circ}$ de julio de 1968, Buenos Aires, Año VI, No 287, pp. 20-22.

22 Emilio Crenzel, Una encuesta de opinión pública en Tucumán bajo la dictadura, Una aproximación indicial. In: Telar. Revista del Instituto Interdisciplinario de Estudios Latinoamericanos, Tucumán, año VI, 2009/2010, No 7-8; Risler, Julia, La acción psicológica. Dictadura, inteligencia y gobierno de las emociones 1955-1981. Buenos Aires: Editorial Tinta Limón, 2018.
} 
Daniel Lvovich, ¿Cerca de la revolución? Datos cuantitativos e interpretaciones de las encuestas sobre las distintas modalidades de apoyo a la violencia revolucionaria en Argentina, 1970 - 1973, Izquierdas, 49, junio 2020:952-967

"El 21 de junio de 1966 entregamos a la opinión pública los resultados de una encuesta (reservada) que pudimos obtener, por nuestros medios, de la Secretaría de Informaciones del Estado, con referencia al gobierno de aquel momento. Una semana después se produjo la Revolución y a partir de entonces, en forma mensual, sobre grupos pilotos semejantes (1.000 interrogados) a los de la encuesta original, proseguimos la investigación por el sistema "al azar callejero" (...) Dos años más tarde pasamos a la investigación trimestral, contando ya con elementos suficientes del pasado para registrar movimientos de opinión. En esta oportunidad el equipo que intervino en este trabajo operó durante los días 14 y 15 de diciembre en la Capital Federal y el Gran Buenos Aires". ${ }^{23}$ La cita de este periódico resulta un indicio relevante acerca de la frecuencia del uso de encuestas públicas, y de su difusión entre un público amplio, al comenzar la década de 1970.

\section{Las encuestas}

La primera encuesta de opinión que incluyó preguntas relativas a la violencia revolucionaria y que fue públicamente conocida se desarrolló entre los años 1971 y 1972, en el marco del proyecto Opinómetro. Medición sistemática de tendencias de la opinión pública" de IPSA. Opinómetro fue un conjunto de encuestas que se desarrolló en cuatro oleadas, entre febrero de 1971 y noviembre de 1972. Cada ola proporcionó una muestra nacional, con un análisis detallado de la opinión en el Gran Buenos Aires, Córdoba y Rosario y varias pequeñas ciudades del interior cuyo impacto se ponderó para alcanzar las proporciones de una muestra nacional. Las preguntas incluyeron una evaluación del optimismo o pesimismo del encuestado con respecto a la situación política y económica del país, su propia situación económica, la nación, la inversión extranjera, la propiedad privada frente a la propiedad pública en las industrias, la valoración de los líderes políticos, y el impacto y motivación de los grupos guerrilleros. ${ }^{24}$ En los resultados de la encuesta, en cada oleada el pesimismo económico se incrementaba, mientras menos de un diez por ciento se manifestaba satisfecho con su propia situación económica. Una proporción igualmente cercana al diez por ciento valoró positivamente la acción de las Fuerzas Armadas, mientras un 70 por ciento mostró distintos grados de rechazo a la acción de los militares en el gobierno. ${ }^{25}$ Mediante la agregación de respuestas a distintas preguntas, los profesionales que trabajaron en la muestra desarrollaron un "índice de actitud hacia el terrorismo".

En la primera ocasión en que fuentes de esta naturaleza fueron empleadas como insumo para una investigación social, Guillermo O’Donnell recurrió a datos de estas encuestas para mostrar que la guerrilla contaba con notable apoyo o simpatía de la población. Los resultados agregados, en función de las encuestas desarrolladas en marzo y octubre de 1971 en las principales ciudades del país son las siguientes, según son presentados por O’Donnell. ${ }^{26}$

Índice de actitud hacia el terrorismo. 1971. Datos agregados

\begin{tabular}{|l|l|l|l|l|}
\hline & $\begin{array}{l}\text { Gran Buenos } \\
\text { Aires }\end{array}$ & Total interior & Rosario & Córdoba \\
\hline Justifica & 45,5 & 49,5 & 51 & 53 \\
\hline No justifica & 51,5 & 48 & 48 & 46 \\
\hline No clasificable & 4 & 2,5 & 1 & 1 \\
\hline
\end{tabular}

${ }_{23}$ Correo de la Tarde, recorte sin fecha correspondiente a diciembre de 1970, en National Archives and Record Administration II, Country Fliles for Argentina, Caja 20.

${ }^{24}$ Turner, op.cit. P. 91Turner sostiene que el clima de opinión demostrado por Opiniometro alentó al gobierno de Lanusse a convocar a elecciones y permitir el retorno al país de Juan Perón.

25 Idem, p. 92

26 Guillermo O’Donnell,. op. cit., 463 - 465 
Daniel Lvovich, ¿Cerca de la revolución? Datos cuantitativos e interpretaciones de las encuestas sobre las distintas modalidades de apoyo a la violencia revolucionaria en Argentina, 1970 - 1973, Izquierdas, 49, junio 2020:952-967

Porcentaje de respuestas que justifican el terrorismo por región, posición social y edad

Posición social
\begin{tabular}{|l|l|l|l|l|l|l|l|}
\hline & Alta & Media & Baja & $\mathbf{1 8 - 2 4}$ & $\mathbf{2 5 - 3 4}$ & $\mathbf{3 5 - 4 9}$ & $\mathbf{5 0}$ y mas \\
\hline GBA & 43 & 43 & 37 & 53 & 48 & 42 & 28 \\
\hline $\begin{array}{l}\text { Todo el } \\
\text { interior }\end{array}$ & 62 & 52 & 46 & 66 & 55 & 49 & 45 \\
\hline Rosario & 80 & 55 & 51 & 76 & 64 & 47 & 56 \\
\hline Córdoba & 51 & 59 & 51 & 68 & 61 & 55 & 39 \\
\hline
\end{tabular}

Considerando en particular que la encuesta indaga por la actitud frente al terrorismo, concepto negativamente connotado, los porcentajes que recogen estas encuestas resultan sorprendentemente altos. El propio O’Donnell destacó la anomalía que supone la casi unánime aceptación de la violencia revolucionaria por las clases altas rosarinas, a la que se estima en un 80 por ciento, superando en mucho a los casos comparables. Más allá de esa evidente inconsistencia, resulta claro que, según esta encuesta, los grupos que otorgaban más apoyo o justificación a la violencia revolucionaria se encontraban entre los jóvenes, las clases medias y altas, y los habitantes del interior del país.

Esta perspectiva resultó aceptada y reiterada en diversos trabajos en los años subsiguientes. ${ }^{27}$ Sin embargo, tres décadas más tarde resultó fuertemente impugnada por Sebastian Carassai, quien cuestionó lo que denomina "el mito de la simpatía inicial" hacia la guerrilla. ${ }^{28}$ Parra ello afirma, siguiendo el análisis de Frederick Turner, basado en datos de Opinómetro que la "respuesta simpática" hacia los "movimientos subversivos" se situaba por debajo de un tercio de la población, aunque omite en este punto el señalamiento de Turner acerca de que la simpatía por la guerrilla era consistentemente más alta en Córdoba que en Buenos Aires. ${ }^{29} \mathrm{La}$ disparidad interpretativa se explica por la metodología que aplicó Opinómetro: la simpatía o antipatía hacia las guerrillas se consignaba en función de respuestas preestablecidas en el cuestionario. De tal modo, afirma Carassai, apoyándose frente a la pregunta que recababa la opinión sobre las personas que integraban los movimientos subversivos el entrevistado tenía tres opciones: "Es la única posibilidad que tienen de expresar su protesta"; "son personas aisladas que responden a su propia necesidad de violencia" y "Es gente que no sabe realmente lo que quiere", derivaba de la primera respuesta simpatía y de las dos segundas antipatía. ${ }^{30}$ Carassai agrega como evidencia que en la medición de Opinómetro de noviembre de 1972, solo un 23,76 \% se pronunció por la respuesta que expresaba simpatía hacia la guerrilla y suma los resultados de la investigación que desarrolló José Miguens en junio de 1971, que muestra que si por un lado la población se mostraba altamente insatisfecha con la situación sociopolítica, por otro la desaprobación hacia los grupos guerrilleros era muy alta. Ante la pregunta " $\mathrm{iA}$ usted le parece que la acción de los grupos terroristas, montoneros, subversivos o como se los quiera llamar, en general merece ser aprobada o desaprobada?" la respuesta desaprobatoria fue del 73,5\% en Capital Federal y el conurbano bonaerense; 70,5\% en Rosario y 62,5\% en Córdoba. Entre los que no respondieron de ese modo, muchos eludieron responder, con lo que el nivel de aprobación a esos grupos fue de un 9,2\% en Capital Federal; 14\% en el Conurbano, 11,7\% en Rosario y 27\% en Córdoba, y en particular entre las clases medias la desaprobación fue mayor a la del promedio de la población. ${ }^{31}$ Asimismo, el autor señala que estos datos guardan coherencia con los de otra medición, realizada en abril de 1970, acerca de las actitudes de la población frente al "terrorismo político", también desarrollada por

27 Maristella Svampa, op. cit ; Marina Adamini, op. cit,

28 Sebastián Carassai,, Los años setenta de la gente común. La naturalización de la violencia, Buenos Aires, Siglo XXI, 2013, p. 122

${ }^{29}$ Idem, p. 123. Turner, op, cit., p. 92

30 Carassai, op. cit, p.123.

${ }^{31}$ Idem, p. 124 
el CIMS de Miguens. Frente a la pregunta de si se debía dar asilo político a los terroristas o se los debía tratar como delincuentes comunes, un 68,9 por ciento optó por esta opción y solo un 12,3\% consideró que tenían derecho al asilo. A la vez, una encuesta de IPSA de 1972 citada por Carassai reveló que un 31 por ciento de la población consideró que se debía castigar con pena de muerte el secuestro de aviones, frente a un 18,9 por ciento que lo hizo en 1970, lo que demuestra- en su perspectiva - un creciente distanciamiento social frente a las acciones violentas. ${ }^{32}$

Las evidencias aportadas por Carassai obligan a matizar las certezas que se desprenden de la lectura de O’Donnell de las encuestas de 1971, aun teniendo en cuenta las criticas metodológicas que ha recibido su libro. ${ }^{33}$ Sin embargo, advertimos un problema interpretativo en la afirmación de Sebastián Carassai referida a que en el estudio de Roberto Pereira Guimarães sobre "apoyos al terrorismo" -basado en los trabajos de Turner- la muestra se redujo significativamente. ${ }^{34}$ Los datos que estudia Pereira Guimarães no son los correspondientes a las sucesivas encuestas de Opinómetro en 1971 y 1972, sino las obtenidas en la investigación conducida por Frederick Turner en agosto y septiembre de 1973. La diferencia temporal no es menor, ya que los sentidos de la lucha armada resultaban radicalmente diferentes en la etapa final de la dictadura militar que en los primeros momentos de la democracia instaurada en mayo de 1973. La encuesta en cuestión que incluyó 890 casos, tenía entre sus objetivos comparar las actitudes de la élite con la opinión nacional en varios momentos. ${ }^{35}$ Por ello, la muestra elegida no buscaba una representación proporcional de la población, al punto que estaba conformada por 120 empresarios de las firmas más grandes del país, 100 integrantes de la sociedad rural y 73 oficiales retirados de las fuerzas armadas, junto a 100 trabajadores rurales de distintas categorías, 199 trabajadores urbanos y 298 miembros de la clase media. Aun con este marcado sesgo, Pereira Guimarães sostiene, efectivamente, que en 1973 el terrorismo no gozaba de un alto grado de apoyo entre los diversos grupos sociales estudiados por Turner, ya que en un 68 por ciento no apoyaban al terrorismo. Sin embargo, el 32 por ciento restante expresaba de modo extremadamente heterogéneo algún grado de apoyo al terrorismo, apoyo que provenía de manera fundamental - aunque no exclusiva, de sectores trabajadores y afines al peronismo. Para Pereira Guimaraes, dicho apoyo puede ser explicado como el resultado de una decisión racional y consciente dada las posibilidades de acción en el sistema político de aquel período. ${ }^{36}$

El análisis de la encuesta de Turner de 1973 permite advertir además el modo en que la formulación de las preguntas resulta fuertemente determinante. La pregunta 18 del formulario es: “¿Cree Ud. que estos cambios [sociales necesarios] deberían realizarse gradualmente o que deben producirse de golpe, usando aún la fuerza o la violencia de grupos especiales? Frente a ello, 653 encuestados respondieron gradualmente, 79 usando la fuerza si es necesario, 6 solo por la fuerza, 43 no sabe y 101 no contesta. Ello implica que en este caso solo el 9,5 por ciento de esta muestra consideraba justificado el recurso a la fuerza en la vida política. La pregunta 19 del formulario de Turner interroga acerca de la percepción de la violencia desplegada hasta entonces, mientras la 19 A inquiría: "Le parece a Ud. que esa cantidad de violencia (lo que dijo en preg. 19) fue la necesaria para llevar al país a las elecciones". En este caso, las respuestas fueron afirmativas en 269 casos, 527 negativas, no sabe 85 y no responde 9. ${ }^{37}$ En

\footnotetext{
32 Ibidem, p.26

33 “... la descontextualización del marco de realización de las encuestas, una dictadura, y la mirada acrítica sobre quien las realizaba, con qué fin y cómo estaban formuladas las preguntas se traducen en un marcado sesgo interpretativo” Emilio Crenzel, “Sebastián Carassai, Los años setenta de la gente común. La naturalización de la violencia. Buenos Aires: Siglo XXI, 2013”. In: Nuevo Mundo Mundos Nuevos. Acceso en 05 julio 2016. < http://nuevomundo.revues.org/66159>.

34 Carassai, op. cit., , 123

35 Turner, op. cit.., 95.

36 Roberto Pereira Guimarães "Understanding supportfor terrorism Through Survey Data: The Case of Argentina” en Turner, Frederick C. \& José E. Miguens ed. Juan Perón and the Reshaping of Argentina. Pittsburgh: University of Pittsburgh Press.1983, pp.200 y 220.

37 Turner,op. cit., 105 y 106, Pereira Guimaraes, op. cit., 208.
} 
este caso, la respuesta afirmativa referida a la efectividad de la violencia para obligar a al régimen a convocar a elecciones fue del 33 por ciento. Dos preguntas acerca de las modalidades dela violencia política, formuladas de modo distinto, dieron como resultado respuestas marcadamente diferentes.

A este conjunto de tres encuestas directamente orientadas al caso argentino y de otras dos que fueron empleadas como indicadores, sumamos otras dos no trabajadas hasta el momento. La primera es la investigación dirigida por Miguens en noviembre de 1970 que muestra índices de aceptación mayores hacia la violencia revolucionaria entre los trabajadores, atendiendo a especificidades regionales y de clase. En efecto, en dicha investigación se afirma que la inmensa mayoría de los trabajadores consideraba que era posible encontrar soluciones a los problemas del país a través del dialogo con el gobierno, más allá de la posición de ese mismo grupo frente a las medidas de fuerza o a las políticas económicas del gobierno, mientras una minoría reducida pensaba que no existía otro camino que la violencia. Los porcentajes que sostenían esa visión eran respectivamente del $81,7 \%$ y el 13,4\%.38Sin embargo -y pese a que la pregunta que se formulaba se refería a si la única solución a los problemas argentinos era la violencia, lo que imponía una opción dicotómica en la que no cabían los matice- se manifestaban grandes diferencias cuando se analizan las respuestas por región. En Córdoba el porcentaje de los que creían que no había otro camino que la violencia era del $41,2 \%$, en Rosario del $22 \%$ en Capital Federal del $11 \%$ y en el Conurbano 10,2 \%. En el caso cordobés, "Entre los que se muestran partidarios de los regímenes de izquierda nacional, los trabajadores de "cuello azul", los trabajadores altamente calificados y los que trabajan en pequeñas empresas para citar solo algunos, los partidarios de la violencia representan un $61,8 \%$ un $45,1 \%$, un $56,1 \%$ y un $49,0 \%$ respectivamente". ${ }^{39}$ En el agregado nacional, los que aceptaban la violencia como solución a los problemas políticos entre los trabajadores de "cuello azul" eran el 23,9\% y un 18,5\% entre los de "cuello blanco", no resultando posible establecer diferencias notables en la formulación de las opiniones según la edad ni el tamaño de las empresas en que se desempeñaran.

La segunda fuente a la que accedimos, es la encuesta realizada en la provincia de Santa Fe, que ofrece una nueva base empírica que contribuye a ampliar el conocimiento de estas temáticas en el marco de un contexto más amplio. La encuesta fue realizada por el "Servicio de Encuestas de Opinión Pública" con sede en Rosario, para el Servicio de Informaciones del Estado. ${ }^{40}$ No contamos aun con datos sobre esta empresa. La encuesta piloto se ejecutó sobre la base del muestreo 1/1000 en Rosario y 1/580 en Santa Fe. En ambos casos se tomó como referencia para la representatividad de la muestra la aplicación según las seccionales electorales de ambas ciudades. En Rosario, considerando una población de 705.000 habitantes según el censo 1970 y con un muestreo de 1:1000 se debían tomar 705 entrevistas personales y en la ciudad de Santa Fe, considerando una población de 231.000 habitantes, se debían realizar 396 entrevistas para obtener una muestra representativa según la relación 1:580. Finalmente fueron sometidas a muestra 707 personas en Rosario (356 varones y 351 mujeres) y 392 en Santa Fe (154 varones y 244 mujeres). El margen de error para Rosario fue de 1,87\% y para Santa Fe del 1,45\%.

La encuesta se administró entre los días 18 al 22 de junio de 1970 en Rosario y entre los días 25 al 31 de junio en Santa Fe Capital. La precisión cronológica es aquí clave: el $1^{\circ}$ de junio de 1970 la organización Montoneros mató al ex presidente de facto Pedro Eugenio Aramburu, lo que no sólo colocó en el primer plano el debate sobre la violencia política, sino que precipitó además una crisis que dio como resultado el desplazamiento de la presidencia del general Onganía y su reemplazo por el general Levingston el día 8 de junio.

El cuestionario constaba de 33 preguntas. Muchas se centraban en la situación económica y otras en la vida política, en particular en la valoración del régimen y de la protesta política y social. ${ }^{41}$ En un

38 UDESA, Archivo Dr Jose E Miguens. Centro de Investigaciones Motivacionales y Sociales. Sindicalismo y política Nacional. Estudio No 93 . Noviembre 1970, pp. $303-305$.

39 Idem, p.306.

40 Archivo Provincial de la Memoria de Santa Fe, Servicio de Encuestas de Opinión Pública. "Encuesta piloto de opinión pública

"desarrollada en junio de 1970 en Rosario y Santa Fe

${ }^{41}$ Presentamos como ejemplos siete preguntas que resultan particularmente significativas: 
Daniel Lvovich, ¿Cerca de la revolución? Datos cuantitativos e interpretaciones de las encuestas sobre las distintas modalidades de apoyo a la violencia revolucionaria en Argentina, 1970 - 1973, Izquierdas, 49, junio 2020:952-967

apartado que solo lleva el título de "Encuesta piloto", pero con la leyenda "reservado", se presentan más de 120 objetivos de la encuesta, desgranados en 45 elementos económicos, 35 políticos y 44 sociales. Entre ellos destacamos los siguientes objetivos: considerar la aceptación del régimen de facto, analizar la imagen de autoridad de las Fuerzas de Seguridad ante la opinión pública, dar cuenta de la repercusión de la actitud de enfrentamiento de un sector de la Iglesia, considerar la repercusión social de la pérdida del poder de la autoridad como consecuencia de los recientemente ocurridos Cordobazo y Rosariazo, "consideración sobre el grado de apoyo a las actividades subversivas de índole estudiantil - gremial", por parte de diversos sectores, comprobar en qué forma es incrementada la proporción de sacerdotes adeptos al "Tercer Mundo" o "Progresistas", considerar la posibilidad de ubicar a los grupos más virulentos "del sector que propicia la violencia y el acceso de las masas al poder", tratar de pulsar las actividades y repercusión efectiva del accionar de los sacerdotes tercermundistas, considerar el apoyo activo y pasivo de los sectores populares a los hechos de violencia y "comprobar la imagen popular de los movimientos subversivos". Probablemente debido a que los objetivos se redactaron con anterioridad al asesinato de Aramburu, no hay entre ellos referencias a ese acontecimiento ni a sus consecuencias en el recambio de los gobernantes al frente del régimen dictatorial.

No contamos en el material disponible con los resultados cuantitativos en bruto de la encuesta, sino con el análisis realizado por dos o más anónimos funcionarios, a los que no hemos podido identificar. A la vez, el grado de detalle y penetración del análisis es mayor en el caso de Rosario que en el de Santa $\mathrm{Fe}$, ya que en este caso el análisis es más sucinto. Aunque en la mayor parte de los casos las respuestas se distribuyen de una manera homogénea entre la población, en ocasiones resultan más claras las variables etaria y de género que las sociales como criterios para agrupar las respuestas en conjuntos consistentes. A la vez, se observan matices regionales entre las respuestas de los habitantes de Santa Fe -más pequeña, burocrática y con fuerte peso de la Iglesia Católica - y los de Rosario, tres veces mayor, con amplio desarrollo industrial y menor peso eclesiástico.

Las posiciones mayoritarias en ambas ciudades eran de disconformidad con las políticas económicas del gobierno militar. Se trataba de unas políticas que habían favorecido la expansión de las infraestructuras y de las inversiones directas de capital extranjero, disminuyendo la participación de los trabajadores en la apropiación de la riqueza nacional. Esa disconformidad se manifestaba también en el plano político. En el caso de Rosario, un 50\% se manifestó en favor de un pronto llamado a elecciones, un $20,8 \%$ en favor de una convocatoria en el plazo de un año, un 9,8\% en dos años, un 3,9\% en tres años, un $2,7 \%$ en un lapso de 5 a 10 años y un $12,7 \%$ para cuando estuvieran dadas las condiciones, existiendo más respuestas femeninas a favor de elecciones prontas. Entre los santafesinos, un 45,5\% se inclinaba por un inmediato llamado a elecciones; un 25\% acordaba en que debían realizarse dentro de determinados plazos (la mitad de ellos en un año), la otra cuarta parte cuando se dieran condiciones favorables. Un sorprendente 4,4 por ciento se inclinaba por que nunca se realizaran elecciones. Se trataba de sectores sociales medios y bajos.

13: ¿Considera que vive bien actualmente o debería vivir mejor?

16: ¿Cuándo considera que debe hacerse un llamado a elecciones?: Enseguida, en un año, en dos años, en 3, en 5, de 5 a 10, cuando se den las condiciones, más de 10 años, nunca

19: ¿Opina Ud. que la acción de las Fuerzas del orden en contra de la subversión es excesiva o débil? Excesiva- débil-correcta 25: ¿Qué opina sobre la conducta estudiantil en la ocupación de las casas de estudio? Es repudiable - es oportuna - representa descontento y es justa - es buena

27: ¿Cree Ud. o no que los sacerdotes del “Tercer Mundo" están vinculados con el comunismo? Si-No

29: ¿Considera Ud. o no, que la violencia y los movimientos subversivos pueden traer alguna solución a los problemas del país? Ninguna solución- alguna solución - puede solucionarlo todo

32: ¿Cree Ud. o no que las Fuerzas de Seguridad están capacitadas para mantener el orden público ante cualquier eventualidad? $\mathrm{Si}-\mathrm{NO}$

También se hacen preguntas de investigación de mercado, referidas a consumos de alcohol, TV, radio, diarios y revistas, pero el análisis de las respuestas no consta en el documento. 
Si consideramos que la demanda de elecciones inmediatas o dentro de plazo breves puede considerarse un indicador de oposición al régimen militar, podemos ubicar dentro de esa clasificación a casi el $71 \%$ de los rosarinos y al $58 \%$ de los santafesinos.

Sin embargo, esta apreciación respecto al régimen militar no se transfería inmediatamente a la valoración de los elementos estrictamente represivos, tal como se deriva del análisis de las respuestas a la pregunta: “¿Qué opina usted, la acción de las Fuerzas del Orden contra la subversión es excesiva o débil?” En el caso de Rosario, el 58,2\% de los encuestados manifestó que la acción represiva era excesiva, predominando entre ellos el grupo etario de 31 a 50 años. Quienes consideraban correcta la represión eran el 23,8\% de los encuestados, entre los que predominan los mayores de 50 años. El grupo que califica como débil la represión es el $18 \%$, con ligera superioridad masculina. Para el caso de la ciudad de Santa $\mathrm{Fe}$, la opinión favorable a las fuerzas represivas abarca un $41,5 \%$ de los encuestados, con predominio femenino. A ellos se agregan las respuestas de quienes consideran que la acción de las fuerzas del orden era débil (24,6\%). Quienes calificaban la represión como excesiva fue el 33,9\% de los encuestados, con ligero predominio femenino. En el caso de las respuestas a esta pregunta en particular, para el caso de Santa Fe, los datos resultan muy confusos, ya que en distintas secciones del análisis de la encuesta se reiteran errores matemáticos e interpretaciones contradictorias. Pese a ello, observamos que en ambas ciudades existía una proporción considerable (más del 40\% en Rosario y más del $60 \%$, en Santa Fe) que avalaban la represión o la consideraban insuficiente, cifras que exceden en mucho al de aquellos grupos que avalaban al régimen en el poder.

La respuesta a la pregunta " ¿Cree Ud. o no que las FF de seguridad están capacitadas para mantener el orden público ante cualquier eventualidad?”, que entendemos permite valorar la opinión sobre las capacidades profesionales de militares y policías, muestra sin embargo resultados poco consistentes en relación al aspecto anterior, sobre todo en el caso de Rosario, en el que el 53,5\% de las respuestas fue positiva, mientras la respuesta aprobatoria en Santa Fe alcanzó un 60 por ciento.

¿Qué ocurre si observamos, en cambio, la actitud frente a los movimientos contestatarios? En relación a la pregunta sobre las ocupaciones de escuelas y universidades por los estudiantes, una modalidad de creciente importancia en el período y que implica sin dudas la adopción de una postura de radical crítica al régimen y al sistema, en Rosario un 47 por ciento de los encuestados manifestó su aprobación. Ese porcentaje incluye un 30,8\% que manifestaba que esa práctica representaba descontento y era justa. Predominan en ese grupo las mujeres de 31 a 50 años y entre los varones el pico está en el rango etario de 18 a 30 años. Tanto para varones como para mujeres está muy representado en estas respuestas el nivel educativo superior. En Santa Fe, un 51 por ciento acepta la conducta estudiantil - con amplio predominio femenino- y $41 \%$ lo consideran repudiable. Las respuestas a la pregunta por el vínculo entre los sacerdotes del Tercer Mundo y el comunismo resulta abrumadora: en Rosario un 74\% y un 83\% en Santa Fe desvinculaban a los sacerdotes tercermundistas del comunismo, lo que implicaba en la coyuntura argentina de 1970 otorgarles una amplia legitimidad.

En este contexto de valoración positiva de las posiciones y prácticas de grupos fuertemente opositores al régimen militar, de predominio de posicionamientos críticos hacia la dictadura que, sin embargo, en el caso de Santa Fe no implicaban un repudio mayoritario de la represión, podemos situar las preguntas sobre la valoración de la violencia revolucionaria en un contexto que le dé sentido.

La formulación de la pregunta dista mucho de ser neutra: “¿Considera Ud o no que la violencia y los movimientos subversivos pueden traer alguna solución a los problemas del país?”. El modo en que se interroga sobre la violencia, un valor negativo si se la presenta de manera aislada y la recurrencia a un término de fuerte connotación negativa, como "subversivo", se suman a una ligazón directa con la solución de los problemas del país que no toma en cuenta las múltiples mediaciones entre las prácticas de violencia revolucionaria y sus objetivos políticos de largo plazo.

Así y todo, en el caso de Rosario las valoraciones positivas distan de resultar ínfimas. El análisis sostiene que el 75 por ciento de la población repele categóricamente los procedimientos violentos, pero que “... las respuestas de tendencia negativa abarcan el otro cuarto de la población encuestada y solo un 
Daniel Lvovich, ¿Cerca de la revolución? Datos cuantitativos e interpretaciones de las encuestas sobre las distintas modalidades de apoyo a la violencia revolucionaria en Argentina, 1970 - 1973, Izquierdas, 49, junio 2020:952-967

2,5\% evidencian una tesitura de neto corte subversivo (puede solucionarlo todo), la que está integrada por un neto dominio de varones en su mayoría jóvenes. Este grupo en la escala de muestreo equivale a 13.000 personas y por los índices bajo en cuanto a cultura, niveles ocupacionales, ingresos y propiedad automotor pueden coincidir con la tipología de la población marginal de Rosario". Entre los que ven en las acciones violentas alguna solución, predominan los varones jóvenes de entre 18 y 30 años y el grupo de entre 31 y 50 años entre las mujeres, con alta representación del nivel educativo superior.

La proporción del $25 \%$ por ciento de los rosarinos encuestados que valoraban positivamente la "violencia subversiva" resultan la mitad en relación con la encuesta de IPSA citada por O'Donnell, pero de más del doble respecto a la cifra que arroja la encuesta de junio de 1970 citada por Carassai. Resulta en cambio compatible con los resultados de la encuesta de noviembre de 1970 realizada por el equipo de Miguens. Estos porcentajes de aceptación distan claramente de resultar insignificantes o irrelevantes, máxime considerando las condiciones de dictadura y represión en que se desarrollaron estas investigaciones sociales.

En el caso de Santa Fe, para el que no tenemos parámetros comparativos, un $85 \%$ de los encuestados respondió que la violencia no podía traer ninguna solución y un 14,8 por ciento respondió que la violencia podía traer alguna solución a los problemas del país. Solo un $0,2 \%$ se inclina hacia la violencia como solución radical, grupo en el que predominaba el nivel educativo primario.

\section{Entre números y conceptos}

Aunque los interrogantes parezcan idénticos, y de hecho hemos hecho un ejercicio de homogenización en nuestra argumentación, las encuestas relevadas preguntan cosas muy distintas e imponen diversas problemáticas Esas formulaciones tienen consecuencias directas tanto sobre las respuestas cuanto sobre las interpretaciones de quienes las formulan. ${ }^{42}$

En la investigación dirigida por Miguens en noviembre de 1970 se interrogaba si la única solución a los problemas argentinos era la violencia, y la pregunta era similar a la formulada en la encuesta santafesina del mismo año, aunque esta última incorporaba la noción propia del discurso contrarrevolucionario de "subversión". Vinculando el ejercicio de la violencia con la solución a los genéricamente descriptos como problemas argentinos, la respuesta a esta pregunta implica alguna forma de adhesión intelectual a las prácticas guerrilleras en función de su efectividad.

En cambio, la encuesta de IPSA de 1971 pregunta por la justificación al terrorismo. Suscribir la afirmación "Es la única posibilidad que tienen de expresar su protesta" no implica adherir a los postulados revolucionarios sino sencillamente colocarse en una posición comprensiva hacia las motivaciones de estos actores. Posiblemente esto explique en parte la elevada cantidad de respuestas afirmativas a este interrogante.

La pregunta de la encuesta orientada por José Miguens en 1971 es más directa, aunque el modo de nominación no contribuye a la neutralidad valorativa: " $¿ A$ usted le parece que la acción de los grupos terroristas, montoneros, subversivos o como se los quiera llamar, en general merece ser aprobada o desaprobada?" Consideramos que aprobar estas prácticas supone un grado de identificación mayor, y que esto explique en parte las cifras más bajas de adhesión en relación a otras encuestas. En este caso también se verifico que una importante cantidad de encuestados se negó a responder, lo que se amolda a la afirmación de Bourdieu en el sentido que mientras más una pregunta plantea problemas conflictivos, más frecuente es en ellas la ausencia de respuesta. Por ello "el simple análisis estadístico de las no respuestas

42 "El efecto de imponer la problemática, efecto ejercido por toda encuesta de opinión y por toda consulta política (empezando por la consulta electoral), proviene de que las preguntas hechas en una encuesta de opinión no son preguntas que todas las personas encuestadas se planteen realmente, y de que las respuestas no son interpretadas en función de la problemática en relación a la cual los encuestados de diferentes categorías han respondido efectivamente". Pierre Bourdieu, "La opinión pública no existe", Debates en Sociologia, Pontificia Universidad Católica de Perú, № 17 1992, p. 307 
aporta una información sobre lo que significa la pregunta y también sobre la categoría considerada, estando ésta definida tanto por la probabilidad de tener una opinión, como por la probabilidad condicional de que dicha opinión sea favorable o desfavorable." 43

Ya hemos mencionado, por último, la marcada diferencia en las respuestas que obtuvo Turner en función del modo de la enunciación de sus preguntas en su muestra que, recordemos, no tenía además pretensión de representatividad.

Pierre Bourdieu ha señalado que las encuestas de opinión resultan, ante todo, un instrumento de acción política, cuya función más importante consiste en imponer la ilusión de que existe una opinión pública como sumatoria puramente aditiva de opiniones individuales; como la media de las opiniones o la opinión media. Por ello, un porcentaje resulta por completo inadecuado para representar el estado de la opinión. En las situaciones en que se constituye la opinión, continúa Bourdieu, las personas se hallan ante opiniones constituidas y sostenidas por grupos, de manera que elegir entre opiniones es, en definitiva, elegir entre grupos. ${ }^{44} \mathrm{Si}$ en nuestros casos rara vez las encuestas aplicadas tenían como objetivo su difusión pública, ya que no buscaban influir de forma directa sobre la opinión de sectores de la población, sino brindar información que orientara las prácticas del estado dictatorial, las observaciones de Bourdieu resultan relevantes en cuanto permiten advertir los límites de los métodos de investigación aplicados, aunque sin invalidarlos por dicha causa. De modo que no hay dudas que las respuestas de los entrevistados no se pueden comprender de ningún modo sin tener en cuenta estas coordenadas, ya que toda respuesta supone una opción entre las alternativas políticas disponibles. En nuestros casos, además, no se puede dejar de considerar que las encuestas se aplicaron en un contexto dictatorial, lo que evidentemente supone un serio condicionamiento al momento de responder. Consideramos asimismo, siguiendo a Laborie que, aunque el estudio de la historia de la opinión depende fuertemente de la naturaleza fugaz de su objeto, su movimiento no es solo el resultado de la traducción directa de reacciones epidérmicas, sino que se deriva de la compleja interacción de profundas tendencias con factores coyunturales.. Con ello, los datos cuantitativos obtenidos dan cuenta de elementos coyunturales, pero sin dudas también reflejan sistemas de creencias mucho más estables y asentados.

Consideramos que las encuestas relevadas resultan útiles para dar cuenta de una serie de informaciones relevantes, en particular cuando ciertos rasgos tienden a reiterarse. Resulta uno de estos datos que el acompañamiento a la violencia revolucionaria era menor en Buenos Aires que en Rosario, y que en la ciudad de Córdoba este apoyo era aún mayor. Mientras en Rosario las cifras de aprobación oscilan en las distintas encuestas entre el 11, 7 y el 51 por ciento, en el de Córdoba esas cifras se ubican entre el 27 y el 53 por ciento. Si se atiende a lo presentado en la encuesta de 1970 dirigida por José Miguens, los porcentajes para el caso de los trabajadores calificados de Córdoba resultan aún más significativos, probablemente debido a la distintiva composición de su clase obrera y la fuerte presencia de distintas expresiones de la izquierda revolucionaria en sus sindicatos durante la Revolución Argentina. Resulta en este sentido significativo que la dirigencia política de la provincia mediterránea - incluidos sectores de la derecha - hayan justificado la violencia revolucionaria al considerarla una respuesta legítima ante la clausura de los canales de expresión democráticos como resultado de la represión del régimen militar. ${ }^{45}$

Esa forma de legitimación de una parte importante de la dirigencia política -a la que podríamos sumar a amplios sectores del mundo intelectual y de la Iglesia Católica - resultó sin dudas extendida en buena parte del país, y contrasta marcadamente con la situación desarrollada con la etapa democrática iniciada en 1973. En efecto, como ha mostrado Marina Franco, a partir del inicio de la "depuración ideológica" del peronismo en 1973 se consolidó la idea de que la guerrilla era un enemigo de la nación a eliminar por todos los medios posibles, se convocó a la participación popular a través de todos los medios

43 Idem, p.304

44 Ibidem, p.303

${ }^{45}$ Leandro Inchauspe, op. cit. 
eficientes para concretar esa faena represiva y se instó a las autoridades de todos los niveles del estado a reprimir con todo rigor los planes del enemigo. De modo simultáneo, la prensa contribuyó a la construcción de una realidad específica, "el imperio de la violencia", ya que, según Franco, a partir de 1973 el discurso dominante comenzó a ser el de la ilegitimidad de la violencia. En este proceso "la violencia de la derecha' y la Triple A siempre tuvieron un rol secundario y subsidiario en relación con la centralidad que se adjudicó a las acciones de la guerrilla de izquierda" .La izquierda fue considerada así como el origen de la violencia "y fue también el punto de llegada cuando, a lo largo de 1975, se transformó en el objeto central del repudio público y de las acciones represivas", con lo que el despliegue represivo "fue muy bien sostenido y alimentado desde el plano discursivo"46 De ese modo, la desautorización, las acusaciones y la persecución promovidas por el mismo general Perón que había alentado el recurso a la violencia pocos años antes, y la casi unánime atribución de la gran prensa y de amplios sectores de la dirigencia política de la responsabilidad por el origen y expansión de la violencia a los grupos revolucionarios minaron sin duda el apoyo social a estos organizaciones

Sin dudas, también el creciente militarismo de las organizaciones revolucionarias, las contradicciones entre sus modalidades de actuación y las propias de las acciones de protesta del movimiento sindical, y -sobre todo- los cambios del contexto dictatorial por uno democrático contribuyeron a su creciente aislamiento y al fin del acompañamiento con el que alguna vez contaron.

Pero ello no puede ocluir retrospectivamente la adhesión que los grupos revolucionarios que abrazaron la violencia política alcanzaron entre los años 1970 y 1972. Es ciertamente altamente probable que las cifras que hiciera publicas Guillermo O'Donnell resulten excesivas como resultado de los diversos factores que hemos señalado, pero de eso no se deduce que el respaldo o la aceptación a la acción de las guerrillas hayan sido insignificantes. Aun considerando que la información provista por las encuestas es solo un indicador aproximado, y aun con las debilidades que hemos presentado a lo largo de este trabajo, la suma de estos estudios sociales nos brinda una herramienta fundamental para determinar las características y límites de un fenómeno tan difícil de aprehender y difuso como lo es el vínculo de una sociedad con las manifestaciones de violencia política que la atraviesan. En este sentido, la marcada heterogeneidad de las respuestas deja en claro que ningún dato social para dar cuenta del fenómeno se puede construir sin delimitar con claridad los indicadores de clase, edad, género y región que los hagan inteligibles. También pone de manifiesto que la opinión es un fenómeno a la vez construido colectivamente y en el largo plazo - tal como se deriva de las enormes diferencias de acuerdo a las variables observadas $-\mathrm{y}$ fuertemente sujeto a las coyunturas políticas.

Siendo casi imposible responder con algún grado de certeza si las respuestas a las encuestas que hemos recorrido implican mucho o poco respaldo a las acciones de las organizaciones revolucionarias, ya que el puro dato cuantitativo que brindan las encuestas es a la vez motivo de opinión. Queda claro en cambio que de ningún modo puede pensarse su emergencia y desarrollo en una relación de pura exterioridad respecto al conjunto de la sociedad. Considerar estos fenómenos requiere, sin duda, enlazar la información cuantitativa aquí presentada con evidencias provenientes de otros registros, de manera de hacer posible aproximarse cada vez mejor al análisis de estas elusivas temáticas.

\section{Bibliografía}

Adamini, Marina, "El consenso social de Montoneros entre 1970 y 1972 [en línea]. Trabajo final de grado. Universidad Nacional de La Plata. Facultad de Humanidades y Ciencias de la Educación, 2009. Disponible en: http://www.memoria.fahce.unlp.edu.ar/tesis/te.549/te.549.pdf,

46 Marina Franco, Un enemigo para la Nación. Orden interno, violencia y "subversión", 1973-1976, Buenos Aires, Fondo de Cultura Económica, 2012, pp. $236-240$. 
Daniel Lvovich, ¿Cerca de la revolución? Datos cuantitativos e interpretaciones de las encuestas sobre las distintas modalidades de apoyo a la violencia revolucionaria en Argentina, 1970 - 1973, Izquierdas, 49, junio 2020:952-967

Anzorena, Oscar, Tiempo de violencia y utopia. Del golpe de Onganía (1966) al golpe de Videla (1976), Buenos Aires, Ediciones del Pensamiento Nacional, 1998

Blanco, Alejandro Blanco, Razón y Modernidad. Gino Germani y la Sociología en la Argentina, Buenos Aires, Siglo XXI

Bourdieu, Pierre"La opinión pública no existe", Debates en Sociologia, Pontificia Universidad Católica de Perú, No 171992.

Calveiro, Pilar, "Antiguos y nuevos sentidos de la política y la violencia" en Lucha Armada en la Argentina, $\mathrm{N}^{\circ} 4,2005$.

Carassai, Sebastián, Los años setenta de la gente común. La naturalización de la violencia, Buenos Aires, Siglo XXI, 2013.

Crenzel, Emilio, Una encuesta de opinión pública en Tucumán bajo la dictadura, Una aproximación indicial. In: Telar. Revista del Instituto Interdisciplinario de Estudios Latinoamericanos, Tucumán, año VI, 2009/2010, No 7-8;

Daniel, Claudia. Números públicos. Las estadísticas en Argentina (1990 - 2010), Buenos Aires, FCE, 2013.

Emilio Crenzel, "Sebastián Carassai, Los años setenta de la gente común. La naturalización de la violencia. Buenos Aires: Siglo XXI, 2013". In: Nuevo Mundo Mundos Nuevos. Acceso en 05 julio 2016. < http://nuevomundo.revues.org/66159>.

Franco, Marina, Un enemigo para la Nación. Orden interno, violencia y "subversión", 1973-1976, Buenos Aires, Fondo de Cultura Económica, 2012.

Gillespie, Richard, Soldados de Perón. Los Montoneros, Buenos Aires, Grijalbo, 1987.

Horowitz, Irving Louis, "Vida y muerte del Proyecto Camelot", en Revista de Ciencias Sociales, núm. 2, junio de 1966.

Inchauspe, Leandro, "No justifico la violencia, pero..." La dirigencia política cordobesa y la lucha armada, Córdoba 1970-1972", Documento de Trabajo No 13 - Córdoba, 2007, disponible en http://historiapolitica.com/datos/biblioteca/cean13.pdf

Risler, Julia, La acción psicológica. Dictadura, inteligencia y gobierno de las emociones 1955-1981. Buenos Aires: Editorial Tinta Limón, 2018.

Lvovich, Daniel, "Gino Germani, Argentine Sociology and the Study of Antisemitism” in Marcel Stoetzler (ed) Antisemitism and the Constitution of Sociology, Lincoln, Nebraska, University of Nebraska Press, 2014. O’Donnell, Guillermo, El Estado Burocrático autoritario, Buenos Aires, Editorial de Belgrano, 1996 [1982] Pereira Guimarães, Roberto, "Understanding supportfor terrorism Through Survey Data: The Case of Argentina" en Turner, Frederick C. \& José E. Miguens ed. Juan Perón and the Reshaping of Argentina. Pittsburgh: University of Pittsburgh Press,1983.

Pozzi, Pablo, Por las sendas argentinas: El PRT-ERP. La guerrilla marxista, Buenos Aires, UDEBA, 2001

Pozzi, Pablo, "Para continuar con la polémica sobre la lucha armada" en Lucha armada en la Argentina, $\mathrm{N}^{\circ}$ 5, 2006.

Pozzi,Pablo "La guerrilla argentina y las masas: el ERP y su inserción", en: Tempo e Argumento, Florianopolis, N¹6, 2015.

Shoai, Andrés, "La estratificación social en loe orígenes de las encuestas de opinión pública en Argentina", IX jornadas de Sociología, Facultad de Ciencias Sociales, Universidad de Buenos Aires, 2011, disponible en: $c d s a . a a c a d e m i c a . o r g / 000-034 / 591 . p d f$

Svampa, Maristella, "El populismo imposible y sus actores" en. Daniel James (dir) Nueva Historia Argentina; tomo 9, Violencia, proscripción y autoritarismo; Buenos Aires, Sudamericana, 2003.

Terán, Oscar, Nuestros años sesenta, Buenos Aires, Punto Sur, 1991.

Touris, Claudia, "Iglesia católica, dictaduras y memorias en conflicto en Brasil y Argentina ", Archives de sciences sociales des religions [En ligne], 170 | avril-juin 2015. URL:

http://journals.openedition.org/assr/26877 ; DOI : 10.4000/assr.26877

Turner, Frederick, "The study of Argentina Politics through Survey Research", Latin American Research Review, 10, 1975. 
Daniel Lvovich, ¿Cerca de la revolución? Datos cuantitativos e interpretaciones de las encuestas sobre las distintas modalidades de apoyo a la violencia revolucionaria en Argentina, 1970 - 1973, Izquierdas, 49, junio 2020:952-967

Vommaro, Gabriel, "Lo que quiere la gente". Los sondeos de opinión y el espacio de la comunicación politica en la Argentina (1983-1999), Buenos Aires, Prometeo, 2008.

\section{Fuentes}

Archivo Provincial de la Memoria de Santa Fe, Servicio de Encuestas de Opinión Pública. "Encuesta piloto de opinión pública "desarrollada en junio de 1970 en Rosario y Santa Fe

Correo de la Tarde, recorte sin fecha correspondiente a diciembre de 1970, en, National Archives and Record Administration II, Country Fliles for Argentina, Caja 20.

Primera Plana, 25 de junio al $1^{\circ}$ de julio de 1968, Buenos Aires, Año VI, Nº 287, pp. 20-22.

UDESA, Archivo Dr Jose E Miguens. Centro de Investigaciones Motivacionales y Sociales. Sindicalismo y política Nacional. Estudio $N^{\circ} 93$, noviembre 1970 